"Y ahora ¿qué?"

\title{
Las revistas políticas argentinas y la muerte de Perón
}

\author{
["And now What?" \\ Argentine Political Magazines and the Death of Perón] \\ Marcelo Borrelli \\ (Universidad de Buenos Aires/CONICET) \\ marcebor@yahoo.com \\ Patricia Orbe \\ (Universidad Nacional del Sur/CONICET) \\ patriciaorbe@gmail.com
}

\begin{abstract}
Resumen:
En Argentina, entre las décadas del sesenta y setenta, se fue desarrollando un intenso clima de discusión política en el marco del cual las revistas de actualidad desempeñaron un rol protagónico. A fin de profundizar en las principales líneas de análisis que orientaron el debate público sobre el acontecer nacional y sobre la posibilidad del retorno del peronismo al gobierno hacia 1973, este artículo aborda la posición editorial de las revistas Panorama, Redacción, Cuestionario, Extra y Carta Política, cinco destacadas publicaciones de la época, ante el nuevo rol de Perón en su regreso al poder en 1973 y la posición que asumieron ante el vacío político que dejó su fallecimiento en julio de 1974.
\end{abstract}

Palabras clave: Perón; Revistas políticas; Peronismo; Prensa argentina; Revistas argentinas

\begin{abstract}
:
In Argentina, between the sixties and seventies, an intense climate of political discussion developed in which topical magazines played a leading role. In order to delve deeper into the main lines of analysis that guided the public debate on national events and on the possibility of the return of Peronism to government towards 1973, this article examines the editorial position of the magazines Panorama, Redacción, Cuestionario, Extra and Carta Política, five outstanding publications of the time, in view of Perón's new role in his return to power in 1973 and the position they assumed regarding the political vacuum left by his death in July 1974.
\end{abstract}

Keywords: Perón; Political magazines; Peronism; Argentine press; Argentine magazines

Recibido: $14 / 01 / 2020$

Evaluación: 06/04/2020

Aceptado: $15 / 06 / 2020$

Anuario de la Escuela de Historia Virtual - Año 12 - N 19 - 2021: pp. 98-121.

ISSN: 1853-7049

http://revistas.unc.edu.ar/index.php/anuariohistoria 


\section{"Y ahora ¿qué?" \\ Las revistas políticas argentinas y la muerte de Perón}

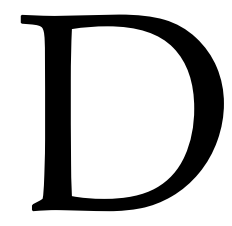

esde la década del sesenta las revistas políticas de actualidad se fueron consolidando como un espacio de debate sobre las principales cuestiones políticas del ámbito nacional. Destinadas generalmente a lectores de clase media y alta, fueron pioneras en ofrecer, además de notas sobre temas variados, una perspectiva analítica y reflexiva sobre la política interna que a su vez distinguía socialmente a sus consumidores. Partimos del supuesto que considera a estas publicaciones como actores políticos (Borrat, 1989) que pretenden incidir en el proceso de toma de decisiones desde la esfera de la influencia. Desde esta perspectiva, su relevancia reside en haber propuesto un análisis en profundidad de la coyuntura política de su tiempo, dándole particular énfasis al género de opinión por sobre el informativo, lo cual las convierte en testimonios centrales para dar cuenta de las lecturas de la realidad nacional que pudieron haber legitimado o deslegitimado las prácticas de los diversos actores políticos de la época.

En este trabajo nos proponemos analizar la posición editorial de las principales revistas políticas de impronta comercial publicadas en 1974 frente a un hecho trascendental de la política argentina: el fallecimiento de Juan Domingo Perón el 1o de julio de ese año. Para ello describiremos la trayectoria de las revistas a analizar (Panorama, Carta Política, Extra, Redacción y Cuestionario), contextualizaremos el momento histórico abierto con el regreso del peronismo al poder en 1973, rastrearemos las interpretaciones editoriales de las revistas ante el rol que Perón estaba ejerciendo en ese nuevo escenario y analizaremos sus evaluaciones frente al vacío político que dejó su deceso. Nuestro objetivo es estudiar posibles continuidades y diferencias en las revistas en su observación del "último Perón", quien había vuelto al poder como "prenda de paz" en un contexto político e institucional convulsionado por la radicalización política, y cuyo rol de moderador en términos generales tenía buena acogida en la prensa política de la época, pero que fue mostrando matices a medida que recrudeció la conflictividad a pesar de sus intentos disciplinadores.

\section{Las revistas}

La década del sesenta y primera parte del setenta en Argentina constituyó una "edad de oro" para los medios de comunicación en general y la prensa política en particular (Getino, 1995). El mercado periodístico de estos años era amplio, diversificado y altamente competitivo, impulsado por un crecimiento económico inusitado y por el inicio de la radicalización y el aumento de la participación popular en la política. En ese 
clima de intensa discusión las revistas políticas de actualidad desempeñaron un rol protagónico y conformaron un espacio de consumo para lectores exigentes, en busca de nuevas informaciones y, más aún, de análisis agudos y originales. Hacia 1974 las revistas analizadas ocupaban un lugar destacado dentro del ámbito de las revistas comerciales de actualidad política.

Panorama, la revista de nuestro tiempo, apareció en junio de 1963 como una publicación mensual de la Editorial Abril (Scarzanella, 2016, p. 151), para pasar, en 1968, a convertirse en un exitoso semanario. Su principal accionista y presidente, César Civita, había fundado Abril en 1941 y su itinerario empresarial exponía un derrotero de sucesos profesionales y comerciales por lo cual a comienzos de los años setenta su empresa editora detentaba una posición dominante dentro de su rama.

La tirada de la revista para el período de estudio fue de 20 mil ejemplares semanales, ${ }^{1}$ estaba orientada a los sectores medios y altos de la sociedad argentina, un público de perfil cosmopolita e interesado en las innovaciones en materia de hábitos y consumos de distinción. Su línea editorial se había acercado al antiperonismo y en las elecciones de marzo de 1973 había apostado por el triunfo de la Unión Cívica Radical (UCR) (Carman, 2015, pp. 502-503).

En Panorama colaboraron muchos periodistas jóvenes en un clima social y cultural de gran efervescencia. En su staff periodístico -definido por Carlos Ulanovsky (1997, p. 228) como "hiperpolitizado"- figuraron algunos colaboradores ligados a la izquierda revolucionaria -peronista y no peronista-, pero las dos personalidades que se sucedieron en la dirección entre 1973 y 1975, Raúl Burzaco y Eduardo Maschwitz, poseían trayectorias políticas y socioprofesionales que los vinculaban a las elites más conservadoras de aquel entonces. En los años estudiados, los principales columnistas sobre la agenda política nacional fueron Jorge Lozano, Jorge Luis Bernetti, Ricardo Cámara y Armando Puente, este último desde Madrid.

Por su parte, el mensuario Redacción se presentó en sociedad en marzo de 1973 con la pretensión de ser "la revista de actualidad mejor informada". Según su director, Hugo Gambini, la perspectiva del retorno del peronismo al poder fue clave para el impulso inicial de la revista: "Se venía el peronismo al gobierno [...], yo no soy peronista y dije 'hagamos una revista crítica'" (H. Gambini, entrevista realizada por P. Gago, 22 de marzo de 2011). Ese perfil opositor al peronismo, característico de su director, impregnará la orientación editorial de la revista. Redacción abarcaba diversos temas, aunque no estaba separada por secciones. La tapa y la nota principal solían estar destinadas a la actualidad política, mientras que en el resto de su edición se trataban cuestiones sobre economía, actualidad sindical e internacional, informaciones del campo cultural y notas de interés general.

\footnotetext{
${ }^{1}$ Instituto Verificador de Circulaciones.
} 
101 I“Y ahora ¿qué?” Las revistas políticas argentinas y la muerte de Perón

Su elenco estable fue liderado por Gambini, ${ }^{2}$ su esposa Emiliana López Saavedra en la coordinación general y Carlos Russo como jefe de redacción, a quienes se sumaba un número variable de colaboradores especiales. Hasta el segundo semestre de 1974 cada edición promedió las 80 páginas y su tirada mensual osciló entre 15 y 30 mil ejemplares (H. Gambini, comunicación personal, 5 de febrero de 2014). Redacción dejará de publicarse en 2003.

También bajo edición mensual se editaba la revista Cuestionario, que lanzó su primer número en mayo de 1973 y se publicó hasta junio de 1976. Esta publicación estaba destinada a un público de clase media politizada y, en particular, se dirigía a un sector de la izquierda intelectual moderada con impronta nacionalista. Su impulsor y director fue el abogado y en ese entonces periodista Rodolfo Terragno, ${ }^{3}$ quien lanzó la revista ante la certeza de que la única forma de hacer "periodismo independiente" era tener un medio propio, producto de las presiones que había sufrido en otras redacciones. Para ese entonces había militado en el frondicismo, según su testimonio tenía una "actitud progresista" y creía en una sociedad más igualitaria, pero no comulgaba con las ideas revolucionarias en boga ( $\mathrm{R}$. Terragno, comunicación personal, 27 de marzo de 2019).

Además del interés central en la política argentina, se destacaron sus notas culturales y sobre temas de "vanguardia" (por ejemplo, el divorcio), ${ }^{4}$ el análisis de otros medios de comunicación, la preocupación por la libertad de prensa, la investigación sobre el poder económico en América Latina y Argentina y la situación de la política internacional. Durante sus tres años de vida Terragno escribió cada una de sus contratapas en clave de editorial. Su tirada en 1973, hasta julio de 1974, fue de entre 22 y 25 mil ejemplares. ${ }^{5}$ Algunos de los colaboradores más destacados de su redacción fueron Lorenzo Amengual, Aída Bortnik, Jack Anderson, Salvador Ferla, Zelmar Michelini, Carlos Ulanovsky, Emilio Corbiere y Gregorio Selser, entre otros.

Extra fue una revista de aparición mensual dirigida por el periodista Bernardo Neustadt que se publicó entre julio de 1965 y mayo de 1989. Sin duda fue el particular estilo periodístico de su director lo que le otorgó a Extra su perfil ideológico definido. ${ }^{6}$ La asistematicidad en ciertas temáticas, la omnipresencia del director, la influencia de la

\footnotetext{
${ }^{2}$ Gambini detentaba una prolífica trayectoria como reportero y redactor de periódicos y agencias noticiosas. Se había iniciado en el periodismo en 1957 en La Vanguardia y trabajó en El Avisador Mercantil, Crítica, Noticias Gráficas, Crónica, Vea y Lea, Leoplán, El Economista, Panorama, Siete Días, Primera Plana y La Opinión.

${ }^{3}$ Columnista de la revista Qué (1964-1965), jefe de Redacción de la revista Confirmado (1967-1968) y columnista del diario La Opinión (1972-1973).

4 "Se presentó un nuevo proyecto en la Cámara de Diputados". (julio de 1973). Cuestionario, (3), p. 20.

5 “El tiraje de esta y otras revistas". (julio de 1973). Cuestionario, (3), p. 24 y "Sumario". (julio de 1973). Cuestionario, (3), p. 4

${ }^{6}$ Neustadt tenía más de 20 años ejerciendo la profesión periodística cuando inició Extra. Durante el primer peronismo, además de su labor periodística, había desempeñado varios cargos de gobierno (Bonasso, 1997: 82; Bosoer, 2013: 222-229; Fernandez Díaz, 2018) y con el derrocamiento de Perón en 1955 iniciaría un rápido proceso de desperonización y, posteriormente, de traspaso a las filas antiperonistas. En 1960 inició su incursión en la televisión, medio en el que con el correr de los años encontraría gran reconocimiento público. Sus contactos con el Estado y con grandes empresas nacionales e internacionales le permitieron construir una lucrativa cartera de auspiciantes para sus emprendimientos periodísticos.
} 
coyuntura y el pragmatismo antes que los análisis de largo plazo fueron algunos de los rasgos destacados de la publicación. De todas maneras, para la época de estudio puede ser ubicada ideológicamente dentro de una perspectiva liberal y de centro derecha, pero entendida dentro de la plasticidad ideológica de su director cuyas opiniones políticas se caracterizaban por ser afines a los oficialismos de turno (Carman, 2015, p. 311).

La publicación se organizó en algunas pocas secciones fijas ("Editorial", "Extra íntimo") y su extensión promedió las cincuenta páginas. El uso de fotografías, fotomontajes e ilustraciones fueron un recurso estilístico distintivo, así como también los titulares de alto impacto. Algunos de sus colaboradores para la etapa bajo análisis fueron Miguel Gazzera, Jorge Aguado, Raúl Cuello, Ricardo Zinn, Osiris Villegas, Carlos Cifuentes y Clara Mariño. ${ }^{7}$ Según Carman (2015, p. 311) hacia la década del 60 llegó a tener una tirada de 45 mil ejemplares, aunque Fernández Díaz (2018, pp. 99-100) señala que la tirada de Extra era "escasa”. Lo que sí era evidente -por sus anuncios publicitarios, su temario, las personalidades entrevistadas y el destinatario al que reconocía dirigirse, es que fue una publicación orientada al poder político y económico de la Argentina, aunque también intentó interpelar al ciudadano de clase media con interés por los temas políticos, financieros e internacionales.

La revista de orientación liberal-conservadora Carta Política tuvo su origen más tardíamente en la segunda quincena de junio de 1974 por la iniciativa del empresario agropecuario y azucarero Raúl Piñero Pacheco, quien estaba interesado en contar con un medio de actualidad como instrumento de posicionamiento político y económico (Piñero Pacheco, 1981, p. 27 y Sivak, 2010, p. 150). Su publicación tuvo dos épocas: de junio de 1974 hasta septiembre de 1975 (dirigida por el abogado y periodista Hugo Martini); y de mayo de 1976 hasta mayo de 1980 (dirigida por el abogado y docente universitario Mariano Grondona, quien había sido columnista en la primera etapa) (Rossi, 2015). En un principio se distribuyó exclusivamente por suscripción que, junto a su orientación ideológica, daba cuenta del tipo de lector al que se dirigía: un público exclusivo y minoritario compuesto por directivos de empresas e instituciones, funcionarios de gobierno y cúpulas castrenses (Raíces y Borrelli, 2019). ${ }^{8}$

Inicialmente se presentó como una revista íntegramente dedicada "al qué y al cómo de la Política y la Economía", temas a los cuales se le otorgaba la totalidad de sus páginas porque en su opinión era "la medida" que se merecían. ${ }^{9}$ Sus páginas interiores no contenían publicidad y se daba preeminencia a artículos extensos que prescindían del rol preponderante de las imágenes. Esta lógica cuasi monográfica, y de un pretendido tinte académico, exigía poseer una competencia interpretativa acorde, propia de quien

\footnotetext{
${ }^{7}$ En sus orígenes, Extra contaba con una redacción ideológicamente diversa, que para esta etapa dio lugar a un perfil más homogéneo alineado con el liberalismo conservador.

${ }^{8}$ A partir del número 11, en la segunda quincena de noviembre de 1974, comenzó a distribuirse en kioscos y su extensión pasó de 24 a 48 páginas. Debido a que no estaba asociada al Instituto Verificador de Circulaciones, no contamos con datos de su tirada para el periodo.

9 "Contratapa". (segunda semana de julio de 1974). Carta Política (2).
} 
103 I“Y ahora ¿qué?” Las revistas políticas argentinas y la muerte de Perón

está habituado a leer informes, formato desde el que se promocionará de hecho desde el número de noviembre de 1974: "Informe político y económico de la quincena".

Por su formato quincenal presentó un fuerte anclaje en la actualidad y puede encuadrarse como un medio de opinión, dado que su contenido regular se compuso casi exclusivamente por artículos firmados. Entre sus principales plumas para 1974 hallamos para el análisis político las de Mariano Grondona, Rosendo Fraga, Rodolfo Pandolfi, Heriberto Kahn, Félix Luna, Jorge Lozano, Carlos Floria y Miguel H. Alurralde; para el económico, Juan Carlos De Pablo. Un staff que por sus adscripciones políticas, sus relaciones profesionales y sus convicciones ideológicas -en suma, por sus trayectorias intelectuales-, compartían un suelo ideológico común en el difuso campo del liberalismo conservador.

\section{Las revistas políticas frente al retorno peronista de 1973 y el nuevo rol de Perón}

Hacia 1973, ante el fracaso del gobierno militar saliente por contener el descontento social y la violencia política, Perón parecía ser el único actor político con capacidad para restablecer el orden y morigerar las reivindicaciones extremas de las organizaciones armadas -a las cuales había alentado desde su exilio madrileño- (Nahmías, 2013). Pero por un obstáculo legal pergeñado por los militares el líder del movimiento no pudo participar de los comicios del 11 de marzo de 1973, por lo cual eligió a su delegado, Héctor Cámpora, como su representante en la contienda electoral. Cámpora contaba con el apoyo del peronismo de izquierda que, en un marco de alta participación popular, desempeñó un rol primordial en la campaña de las elecciones que consagraron el triunfo del Frente Justicialista de Liberación (FREJULI). ${ }^{10}$ Con su llegada al poder, las juventudes ligadas a la "Tendencia Revolucionaria" del peronismo experimentaron una verdadera FF"primavera política" que se expresó en un protagonismo sin precedentes de ese sector surgido al calor de la movilización antidictatorial (Manzano, 2017). Sin embargo, ya desde los momentos previos a la asunción de Cámpora, el propio Perón comenzó a dar señales evidentes de apoyo a la "derecha" de su movimiento, conformada por los sindicatos, los peronistas históricos, dirigentes diversos vinculados al nacionalismo de derecha y el grupo en torno al ascendente José López Rega, el secretario privado de Perón y ministro de Bienestar Social de Cámpora. Ello quedó claramente expuesto luego de la escenificación pública del conflicto entre ambas tendencias que significó la "masacre de Ezeiza", cuando el propio Perón llamara a disciplinar a los sectores revolucionarios de izquierda que integraban el movimiento (Perón, 1974, pp. 49-52). ${ }^{11}$

\footnotetext{
${ }^{10}$ Un frente de partidos liderado por el peronismo que se completaba con el desarrollismo y pequeños sectores desprendidos del socialismo, el radicalismo y los conservadores populares.

${ }^{11}$ En el marco de esta ofensiva, Cámpora se vio obligado a renunciar el 13 de julio de 1973, ya con la abierta desconfianza de Perón (Csipka, 2013). Posteriormente asumió la presidencia Raúl Lastiri, presidente de la Cámara de Diputados y yerno de José López Rega, en una maniobra prohijada por el secretario privado de Perón.
} 
Este desplazamiento de los sectores revolucionarios de izquierda se dio en el marco de un acercamiento de Perón hacia los partidos políticos de la oposición, fundamentalmente el radicalismo, y un discurso que fundaba el nuevo momento en la "unión nacional". Sin embargo, como señala Tcach (2002, pp. 74-76), lo que había nacido con la "doctrina Ezeiza" era un "doble discurso", que junto a las apelaciones a la paz, la democracia y la unidad nacional convalidaba la impunidad para quienes desde el Estado -o desde las facciones amigas- se propusiesen eliminar al adversario político.

¿Cómo observaron las revistas el retorno peronista y el nuevo rol que tomaba Perón en la política argentina? En el caso de Panorama, desde sus orígenes había estado signada por una línea editorial de perfil antiperonista y en consecuencia apostó por la llegada al ballotage en las elecciones presidenciales del 11 de marzo del candidato de la Unión Cívica Radical (UCR), Ricardo Balbín. ${ }^{12}$ Pero una vez consumada la victoria del peronismo adoptaría una posición contemporizadora y condescendiente hacia el nuevo poder político y sus principales referentes (Orbe y Napal, 2019). Luego de la asunción del nuevo gobierno -aunque no dejó de mencionar que el regreso peronista encerraba "un buen número de interrogantes", ${ }^{13}$ con eje en su "lucha tendencial" interna- ${ }^{14}$ anunció con entusiasmo la "restauración justicialista" y señaló al peronismo como "la fuerza más sólida y progresista que admite el entourage del poder", ${ }^{15}$ más allá de las limitaciones que implicaba su "heterogeneidad". ${ }^{16}$

Durante esos primeros meses de 1973 las representaciones en torno a la figura de Perón pendularon entre la imagen de fragilidad física por su avanzada edad y la de la vigencia de su rol como conductor. La primera impresión se expresó en los momentos previos a la elección de marzo de 1973,17 donde aún se estaba discutiendo qué posición adoptaría el gobierno militar ante los comicios y sus resultados. Si bien el estado de salud del líder peronista fue una temática que habría de reaparecer con cierta recurrencia en el temario de la revista -especialmente en las columnas de Jorge Lozano, ante el inminente triunfo del FREJULI la idea de "vigencia" del liderazgo del "caudillo justicialista" se impuso con fuerza, en tanto se lo valoraba como un "político excepcional"18 y "árbitro de la situación" de la interna peronista-. ${ }^{19}$

Una vez que Perón pareció retornar al centro de la escena, los editores de Panorama despertaron en sus lectores grandes expectativas sobre las posibilidades de que lograra

\footnotetext{
12 “Encuesta: Ganan Cámpora, Balbín y Manrique”. (8 al 14 de febrero de 1973). Panorama, (302), p. 22.

${ }^{13}$ Lozano J. (15 al 21 de marzo de 1973). “La Argentina. Elecciones: Perón sabe y puede”. Panorama, (307), p. 12.

14 "El difícil equilibrio". (29 de marzo al 4 de abril de 1973) Panorama, (309), p. 11; "La Argentina. Al borde de las definiciones". (26 de abril al 2 de mayo de 1973). Panorama, (313), p. 12.

${ }^{15}$ Lozano J. (24 al 30 de mayo de 1973). “La Argentina. El gobierno de los argentinos. Panorama, (317), p. 12.

${ }^{16}$ Lozano J. (5 al 11 de julio de 1973). “El silencio de 40 días”. Panorama, (322), p. 11.

17 “La Argentina. El gobierno veranea y el tirano acecha”. (11 al 17 de enero de 1973). Panorama, (298), p. 13; "Justicialismo. Gerovital H3 y el protocolo socialista". (15 al 21 de febrero de 1973). Panorama, (303), p. 14. 18 "La Argentina. 11 de marzo: el miedo a la verdad". (8 al 14 de marzo de 1973). Panorama, (306), p. 13.

19 "El fallo popular". (15 al 21 de marzo de 1973). Panorama, (307), p. 11.
} 
105 I“Y ahora ¿qué?” Las revistas políticas argentinas y la muerte de Perón

"la pulverización de las antinomias" dentro de su movimiento. ${ }^{20}$ En ese marco, se lo presentó optando tácticamente por la moderación, ${ }^{21}$ convertido en "el dirigente más lúcido que ofrece la clase dirigente argentina", ${ }^{22}$ aunque condicionado por su avanzada edad, circunstancia que "le daba poco tiempo para lograr la nueva síntesis, necesaria para que el país supere la anarquía y alcance la unidad nacional". ${ }^{23}$ De allí que se resaltara positivamente su acercamiento a Balbín, como uno de los gestos que materializaba los esfuerzos por superar las antinomias del pasado. ${ }^{24}$

Por su parte, para Redacción, el peronismo era un movimiento de dinámica incierta que se definía por la habilidad de Perón para "mover sus piezas", 25 a quien definía como un "un rey incólume" que jugaba al ajedrez. ${ }^{26}$ Pero mientras que, por un lado, se reconocían sus dotes de conductor, por otro, se recordaba a los lectores las viejas denuncias de corrupción ligadas a las primeras presidencias peronistas del ' 46 al ' $55 .{ }^{27}$

En los días previos al retorno definitivo del líder peronista al país, atravesado por la convulsiva interna del oficialismo, Gambini advertía a sus lectores que esperar que Perón viviera eternamente como una "solución mágica" era una clara manifestación de la "inmadurez que solemos exhibir los argentinos". ${ }^{28}$ Luego, Redacción expuso sin tapujos la interna peronista y sus consecuencias lacerantes a partir de los sucesos de Ezeiza. Con Perón definitivamente instalado en el país, la revista destacó su "giro a la derecha" y el hecho que "el verdadero centro de poder oficial" se ubicara en su residencia en la localidad de Vicente López, por lo que el país estaba siendo conducido desde las sombras por un "gobierno paralelo". ${ }^{29}$ En ese contexto, se presentaron las renuncias del presidente Cámpora y el vicepresidente Vicente Solano Lima como un producto del "peronazo", es decir: "un golpe de Estado dentro del propio Gobierno". ${ }^{30}$ La publicación no cejó en su severo juicio sobre la crisis institucional previa a las elecciones de septiembre, al enfatizar sobre la dependencia del sistema político nacional en relación a su figura, al decir que “bastó que Perón se resfriara, que un famoso

\footnotetext{
${ }^{20}$ Lozano J. (29 de marzo al 4 de abril de 1973). “La Argentina. Cinco puntos: la frontera crítica”. Panorama, (309), p. 12.

21 “25 de Mayo de 1973: El nuevo amanecer peronista”. (10 al 16 de mayo de 1973). Panorama, (315), p. 14.

22 “La Argentina. El gobierno de los argentinos". (24 al 30 de mayo de 1973). Panorama, (317), p. 12.

${ }^{23}$ Lozano, J. (28 de junio al 4 de julio de 1973). “Juan Perón, el descarnado”. Panorama, (321), p. 11.

24 "El árbitro y la economía". (28 de junio al 4 de julio de 1973). Panorama, (321), p. 9; "El nacimiento del Partido Nacional". (5 al 11 de julio de 1973). Panorama, (322), pp. 6-7. Posteriormente Panorama apostará abiertamente a la concreción de una fórmula electoral de "unidad nacional" Perón-Balbín para las elecciones de septiembre de 1973. Cámara R. "Perón-Balbín (I): La hora de hamacarse". (19 al 25 de julio de 1973). Panorama, (323), pp. 4-5; "El fragor de la confluencia”. (19 al 25 de julio de 1973). Panorama, (323), pp. 6-7.

${ }^{25}$ Gambini, H. (mayo de 1973). “La entrega del Gobierno”. Redacción, (3), p. 5.

${ }^{26}$ Russo C. (mayo de 1973). “Las milicias murieron antes de nacer”. Redacción, (3), p. 16.

27 “El convenio firmado con la ITT en 1946”. (mayo de 1973). Redacción, (3), p. 52.

${ }^{28}$ Gambini, H. (junio de 1973). “Los Montoneros y el ERP”. Redacción, (4), p. 5.

${ }^{29}$ Gambini, H. (julio de 1973). "El gobierno paralelo". Redacción, (5), p. 5; “A los 30 días, el giro a la derecha”. (julio de 1973). Redacción, (5), p. 12.

${ }^{30}$ Gambini, H. (agosto de 1973). "Los efectos del peronazo". Redacción, (6), p. 5. Similar argumentación en torno al golpe de Estado interno presentó Cuestionario: Terragno, R. (agosto de 1973). "El futuro de Perón". Cuestionario, (4), contratapa.
}

Anuario de la Escuela de Historia Virtual - Año 12 - № 19 - 2021: pp. 98-121. ISSN: 1853-7049 
cardiólogo lo visitara diariamente para que una nueva sensación de angustia alimentara la usina de rumores" ${ }^{31}$ El diagnóstico que el mensuario proyectaba de este modo sobre el corto plazo resultaba lapidario.

En Extra el retorno del peronismo despertó amplias expectativas, principalmente por considerar que Perón se situaba en el "centro" político al rechazar la radicalización ideológica -principalmente de la izquierda- y que aseguraba la defensa de las instituciones y de un capitalismo ordenado (Iturralde y Borrelli, 2019). Dentro de ese marco general, Extra exigió no "temerle a la verdad de la urna" luego del triunfo de Cámpora y reconocer el triunfo del peronismo, aunque se mostró preocupado sobre qué sector del oficialismo gobernaría realmente, si los más "reformistas" o los que proponían el "socialismo nacional" ${ }^{32}$ En esta línea, tempranamente denunció con vehemencia que los sectores de la izquierda peronista, con el "pretexto" del "trasvasamiento generacional" intentaban en realidad el "trasvasamiento ideológico", 33 acusándolos de "intrusos", "marxistas infiltrados" y "contrabandistas ideológicos", en un tono discursivo fuertemente excluyente afín al sindicalismo peronista. ${ }^{34}$ Ante esta disputa que crecía en el peronismo, para la revista el único que podía definir la identidad peronista era su líder, cuya actitud de centro - que la revista reivindicaba como una posición propia que antecedía a la actitud de Perón-35 aseguraba que la resolución no virara hacia la izquierda.

Para Cuestionario las elecciones del 11 de marzo habían decretado el "triunfo de la realidad" frente a la intención de los opositores al peronismo de negar su existencia en la política nacional. ${ }^{36}$ Pero tempranamente advirtió que la coalición triunfante albergaba "corrientes incompatibles" en su seno que obligarían a un intenso debate ideológico y manifestaba su inquietud por las "actitudes séctareas [sic]" y el "dogmatismo de aquellos grupos mesiánicos que se consideran depositarios de la verdad revolucionaria" ${ }^{37}$ La clave del retorno al poder era que Perón comprendiera lo que sus bases demandaban, que no era meramente replicar el modelo del primer peronismo, sino una "política de transformación" que, sin "comportarse como el orangután en el bazar", satisficiera a una población ansiosa de "cambios sustanciales". 38

En los meses posteriores la revista tendió a interpretar las acciones de Perón que pusieron freno a los sectores revolucionarios del peronismo como parte de su "pragmatismo" y su necesidad de mantener bajo control al movimiento. ${ }^{39}$ Dentro de ese

\footnotetext{
${ }^{31}$ Gambini, H. (setiembre de 1973) “La Sombra de Cámpora”. Redacción, (7), p. 5.

${ }^{32}$ Neustadt, B. (abril de 1973). “'Seamos adultos!: Campora es el presidente”. Extra, (94), p. 7.

${ }^{33}$ Neustadt, B. (mayo de 1973). “En las manos de Perón”. Extra, (959), p. 15.

${ }^{34}$ Con el que Extra mantenía buenas relaciones, a través por ejemplo del dirigente sindical peronista y miembro fundador de las 62 Organizaciones Peronistas, Miguel Gazzera, quien era habitual colaborador de la revista.

35 “Ahora lo dijo Perón”. (julio de 1973). Extra, (97), p. 13

36 Terragno, R. (mayo de 1973). “El triunfo de la realidad". Cuestionario, (1), p. 28.

37 “Cuál es la posición política de CUESTIONARIO”. (mayo de 1973). Cuestionario, (1), p. 2.

38 Terragno, R. (mayo de 1973). "El triunfo de la realidad". Cuestionario, (1), p. 28.

${ }^{39}$ Terragno, R. (julio de 1973). “El pueblo protagonista”. Cuestionario, (3), contratapa.
} 
107 I“Y ahora ¿qué?” Las revistas políticas argentinas y la muerte de Perón

arco interpretativo, destacó que no era un ideólogo sino un conductor, que sus actos estaban guiados por cuestiones "tácticas" y no doctrinarias, y que por ende no era un "purista" que se preocupara por la "congruencia intelectual" (en referencia, por ejemplo, al apoyo que le había brindado a los sectores revolucionarios en los años previos). ${ }^{40}$

Si bien Carta Política nació más de un año después del retorno peronista, puede afirmarse que una de las coincidencias existentes entre sus numerosos colaboradores algunos de los cuales mantenían sus convicciones antiperonistas inalteradas- radicaba en la valoración positiva de la estabilidad del régimen republicano y representativo recuperado a partir de mayo de 1973. En ese ámbito, Jorge Lozano -quien había abandonado Panorama y se había sumado a esta iniciativa periodística- aseguraba en el primer número de la revista en junio de 1974 que el tercer gobierno de Perón iniciado en octubre de 1973 era una "victoria del orden y la sensatez política" que erigía un "orden genuino [...] aceptado por la mayoría de los habitantes [del] país". ${ }^{41}$

\section{El "último" Perón y su muerte en julio de 1974}

Perón falleció el 1o de julio de 1974 ejerciendo el cargo de presidente de la Nación que había asumido el 12 de octubre de 1973 (luego de su triunfo en las elecciones del 23 de septiembre de ese año junto a su esposa y candidata a vicepresidenta Isabel Perón). Los principales temas que hegemonizaron su tercera presidencia fueron la espiralización del conflicto interno en el movimiento peronista; el incremento de la violencia política; el agravamiento de su confrontación con la Tendencia Revolucionaria -particularmente con la organización político-armada Montoneros- y los problemas económicos vinculados al Pacto social, el acuerdo ungido en junio de 1973 entre el Estado, los sindicatos y los empresarios que aseguraba una política de ingresos concertada y que fue uno de los pilares de la estrategia de conciliación de Perón (Garategaray, 2009, p. 15). Ante este escenario de conflictos graves y abiertos, la eventualidad del fallecimiento del líder peronista debido a su avanzada edad fue un tema omnipresente en lo análisis políticos del momento por el temor de un agravamiento de todas las variables en juego.

¿Qué aspectos destacó Panorama en este contexto? En vísperas de las elecciones de septiembre la revista volvió a expresar su preocupación por la integridad física del candidato justicialista, ${ }^{42}$ en tanto Jorge Lozano lamentaba que la "suerte del país" estuviera subordinada a la "salud o la inteligencia de un hombre", al punto de afirmar que aún el antiperonismo "enciende las velas para rogar que Perón viva, por lo menos, hasta el término de su mandato". ${ }^{43} \mathrm{Al}$ mismo tiempo se presentaba a un Perón "sagaz e inteligente" que había logrado hacer girar al justicialismo "hacia su viejo cauce

\footnotetext{
${ }^{40}$ Terragno, R. (febrero de 1974). "Perón, de enero a enero". Cuestionario, (10), contratapa.

${ }^{41}$ Lozano, J. (tercera semana de junio de 1974). “La patria infantil”. Carta Política, (1), p. 13.

${ }^{42}$ Lascano, F. (20 al 26 de setiembre de 1973). “La Argentina. Perón: a cien horas del poder”. Panorama, (331), p. 5.

${ }^{43}$ Lozano, J. (4 al 10 de octubre de 1973). “De Onganía a Perón”. Panorama, (333), p. 11.
}

Anuario de la Escuela de Historia Virtual - Año 12 - Nº 19 - 2021: pp. 98-121. ISSN: 1853-7049 
ortodoxo", 44 inaugurando una nueva etapa signada por la llegada del "centrismo al poder", una apuesta por el "orden" y la "alianza con los moderados de signo "nacional" ${ }^{45}$ En particular celebraba lo que entendía como el fin del "pendulismo", en tanto el General había dispuesto la "depuración antiizquierdista en el movimiento mayoritario" en una "guerra declarada al marxismo". ${ }^{46}$ En efecto, a inicios de octubre de 1973 el Consejo Superior Justicialista emitió una "orden reservada" que promovió la "guerra contra los grupos marxistas" dentro del peronismo y que daría inicio formal a la "depuración ideológica" contra la izquierda peronista (Bufano y Teixido, 2015, pp. 145-152; Franco, 2012, p. 51; Godio, 1986, p. 241; Servetto, 2010, pp. 196-200; Terragno, 2005, pp. 57-58; Yofre, 2010, pp. 151-152).

Ante la muerte de Perón, la dirección de Panorama puso de manifiesto su apoyo "ecuánime y desinteresado" al nuevo gobierno en la nueva coyuntura "tan difícil", aunque la tapa de la edición proyectaba una imagen de Isabel con los ojos cerrados signada por el "dolor", la preocupación y cierto desconcierto (Figura 1). ${ }^{47}$ El funeral contó con una extensa cobertura a la par que se destacó la suma de apoyos que había recibido la nueva presidenta, entendiéndolo como un símbolo de "la primera acumulación de poder producida en el país, luego de la enfermedad y muerte de Perón". ${ }^{48}$ Sin embargo, la apuesta de la revista se orientaba hacia otro proyecto: la consolidación de Balbín como "el hombre clave de la crisis". ${ }^{49}$ Inclusive especuló con un "eventual ingreso de la UCR al gabinete", aunque ante la falta de concreción de ese trascendido continuó destacando el buen diálogo de Balbín con otros actores políticos, como las Fuerzas Armadas, y su "oposición constructiva” y "sin estridencias", conducta que lo proyectaba al "primer puesto de la política nacional". ${ }^{50}$

\footnotetext{
${ }^{44}$ Ibid.

45 “El centrismo al poder". (11 al 17 de octubre de 1973). Panorama, (334), tapa; "La Argentina. ¿Un gabinete para cinco meses". (11 al 17 de octubre de 1973). Panorama, (334), pp. 4-5.

${ }^{46}$ Cámara, R. (4 al 10 de octubre de 1973). “Depuración: El péndulo se detuvo”. Panorama, (333), p. 4.

${ }^{47}$ Burzaco, R. H. (9 al 15 de julio de 1974). "Carta del director." Panorama, (369), p. 3.

48 “El poder después de Perón”. (9 al 15 de julio de 1974). Panorama, (369), p. 12.

${ }^{49}$ Ibid.

50 “La táctica de Balbín: sin estridencias, la UCR se repliega”. (16 al 22 de julio). Panorama, (370), pp. 14-16.
} 
Figura 1. ¿Una presidenta que prefiere no ver? Panorama, entre la necesidad del "acuerdo" y un futuro incierto

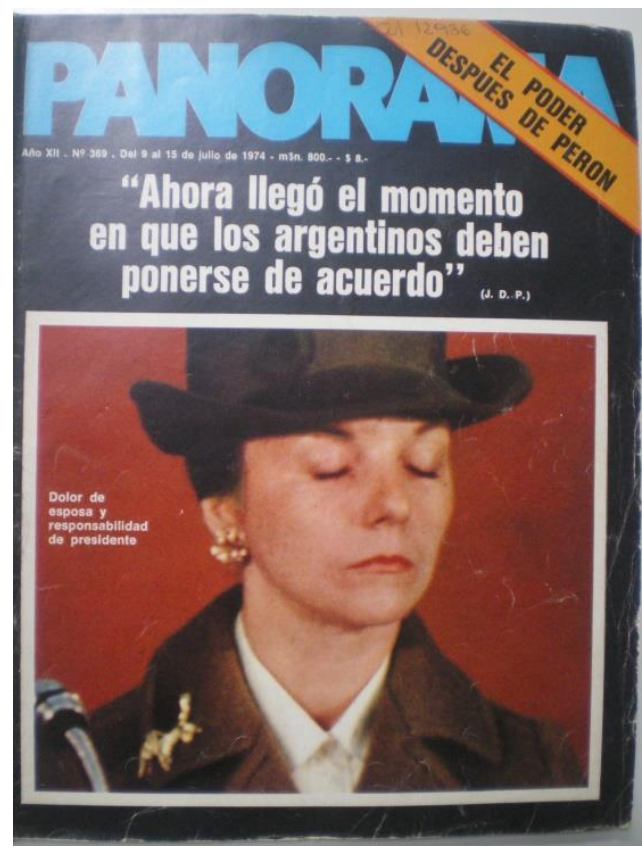

Fuente: julio de 1974, Hemeroteca de la Biblioteca del Congreso de la Nación Argentina.

Extra, luego del triunfo peronista, se ubicó a tono con la nueva coyuntura y subrayó el empoderamiento de Perón: en su portada de octubre de 1973 simuló un cheque en blanco extendido al nuevo presidente por los más de siete millones de votantes que habían elegido la fómula Perón-Perón (Figura 2). Esta posición se ampliaba en el editorial de la edición, titulado con el elocuente "Perón al poder, con todo el poder", donde expresaba que los votantes lo concebían como el "único político argentino con capacidad de aglutinamiento, de concluir con los estertores de la violencia, de organizar el país y de sacarnos el fantasma de la guerra civil de encima". ${ }^{51}$ Como lo había mencionado en el retorno de 1973, Perón proponía un país de "centro", y los militantes a derecha e izquierda debían dejar de batallar en pos de su protagonismo, ya que de otro modo los "adversarios" aprovecharían el fracaso para retrotraer al país a sus "frustraciones anteriores". ${ }^{2}$

\footnotetext{
${ }^{51}$ Neustadt, B. (octubre de 1973). “Perón al poder, con todo el poder". Extra, (100), p. 14.

52 “Para un peronista no hay nada mejor que... ¿qué?". (noviembre de 1973). Extra, (101), p. 14.
} 


\section{Figura 2. Extra y un cheque en blanco extendido a Perón tras su victoria en las elecciones del 23 de septiembre de 1973}

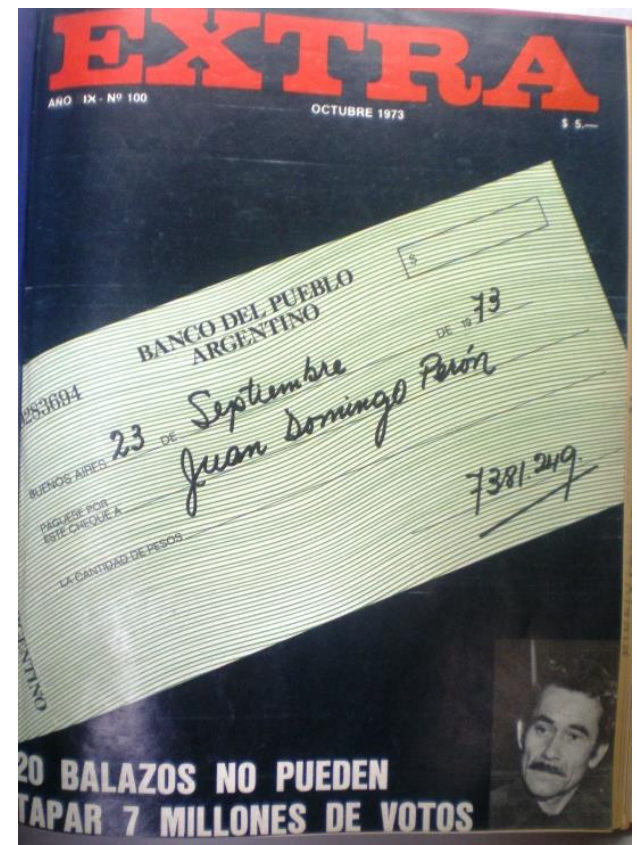

Fuente: Octubre de 1973. Hemeroteca de la Biblioteca del Congreso de la Nación Argentina.

La muerte de Perón encontró a Neustadt en Amsterdam, desde donde reconocía el impacto de la noticia: "Me estremecí. Como el país", manifestaba. Para el director de Extra, Perón se había ido "en su plenitud" y en condiciones de transformarse en un "hombre de leyenda": "Reivindicado por sus adversarios, respetado por los indiferentes, amado por su pueblo. No tuvo ni tiempo de ser alcanzado por los rayos de ningún fracaso. Un mito irrasguñable". Si bien con él morían "30 años de vida política dura, frenética" nacía también la Argentina "de la concordia", siempre y cuando los que estuvieron a su lado "oyeron bien y escucharon mejor". La esperanza de Neustadt sobre este intérprete no surgía del partido del líder desaparecido, sino -en el mismo tono que Panorama y, como veremos, también de Carta Política-, del radicalismo: Balbín había sido "el que mejor lo entendió", por lo que, con su particular estilo retórico, aseguraba: "Falta ahora un nuevo protector del Estado ¿Ricardo Balbín? Tal vez...". Sobre el rol de Isabel, se reconocía que no tenía experiencia política, pero que si elegía bien a sus colaboradores la Argentina podía "escapar del filoso precipicio". ${ }^{53}$

La posición expresada por Neustadt en términos personales se revalidaba en la tapa y en el editorial de la edición. La portada puso eje en el desafío a futuro que implicaba la ausencia de Perón. Bajo su imagen de perfil expresaba "El destino cita a los argentinos" (Figura 3), título que encabezaba el editorial donde manifestaba cierta esperanza en la continuidad del camino de la "unión nacional" trazado en vida por el presidente. Para ello, el "deber" de los argentinos en la hora era "seguir unidos detrás

\footnotetext{
${ }^{53}$ Neustadt, B. (julio de 1974). “El día que murió Perón”. Extra, (109), p. 5.
} 
de quien le ha sucedido", "estrechar filas" y colaborar con la "superación de los intereses sectoriales". La nueva presidenta encontraría "escollos en su camino", pero ya tenía la "ruta trazada y el apoyo unánime de su pueblo". ${ }^{54}$

\section{Figura 3. Extra: La muerte de Perón como un desafío para todos los argentinos}

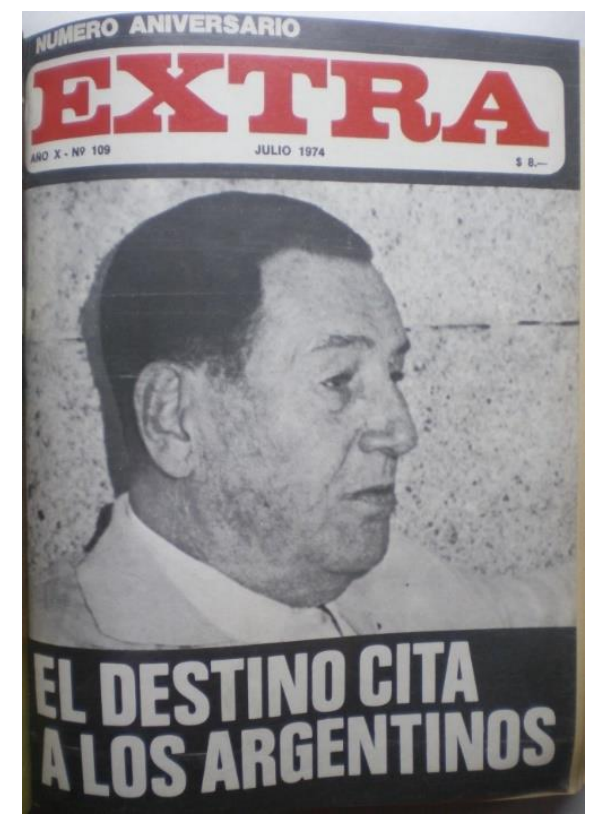

Fuente: julio de 1974, Hemeroteca de la Biblioteca del Congreso de la Nación Argentina.

Por su parte, en las semanas subsiguientes a la asunción presidencial de Perón, Redacción continuó insistiendo sobre la gravedad de las divisiones internas del peronismo y los esfuerzos del primer mandatario para encarar la "depuración ideológica" dentro de las filas del movimiento. ${ }^{55}$ Acto seguido, Gambini dedicó un editorial completo a la cuestión de la integridad física del presidente entendiéndola como "un asunto de Estado", donde enumeraba una serie de factores considerados determinantes, como sus 78 años y el "fatalismo biológico", los excesivos "esfuerzos" que implicaba la investidura presidencial y a la vez la "atención" del liderazgo del movimiento. Todo ello conduciría a una coyuntura alarmante, por la cual afirmaba que "los argentinos asistimos preocupados al macabro juego de intereses políticos que se desata cada vez que Perón estornuda". ${ }^{56}$ Ante esta incertidumbre el mensuario lamentaba que el movimiento justicialista careciera aún de "una estructura sólida que canalice la sucesión de su caudillo", situación que dejaba al país a merced de la "sórdida batalla por la herencia política" librada entre los distintos sectores en pugna por usufructuar su legado". ${ }^{57}$

\footnotetext{
54 "El destino cita a los argentinos". (julio de 1974). Extra, (109), p. 15.

${ }^{55}$ Gambini, H. (noviembre de 1973). "El pleito del peronismo". Redacción, (9), p. 5; Delgado, O. (noviembre de 1973). “El peronismo se va uniformando". Redacción, (9), p. 12.

${ }^{56}$ Gambini, H. (diciembre de 1973). “La salud de Perón”. Redacción, (10), p. 5.

57 “La herencia de Perón y sus sucesores”. (diciembre de 1973). Redacción, (10), p. 12.
} 
El panorama político nacional que proyectaba la revista en el primer semestre de 1974 era por demás preocupante, signado por el verticalismo, la censura a los medios, el desgaste del gobierno ante la falta de resultados y las promesas incumplidas a su masivo electorado. ${ }^{58}$ En tanto, se señalaba positivamente el acercamiento constructivo de la oposición partidaria como un mecanismo de compensación ante la crítica situación interna del oficialismo y el "peligro de un vacío de poder". 59

La muerte del presidente impactó en Redacción como en el resto de sus pares de modo que lanzó en el mes de julio de 1974 una edición especial de 100 páginas donde reflexionó sobre el futuro inmediato del país. La principal preocupación esbozada desde su tapa se centraba en "Quiénes van a gobernar ahora" (Figura 4), nota en la que se especulaba sobre los roles que desempeñarían las Fuerzas Armadas, los sindicatos, la oposición y el ahora empoderado López Rega, entendiendo que “el vacío que deja Perón en la política argentina, no lo podrá cubrir una sola persona, sino varias". ${ }^{60}$ El propio Gambini sentenciaba que se clausuraba "una etapa de decisiones unilaterales" y comenzaba otra de perfiles inciertos: la del "peronismo sin Perón". Seguidamente, al juzgar que "si el peronismo no se institucionaliza, se quiebra", exponía sus anhelos en relación a que lograra funcionar de manera más orgánica -como lo había hecho la UCR luego de la muerte de Yrigoyen- en función de los desafíos que tenía por delante en la conducción del país. ${ }^{61} \mathrm{Y}$ precisamente al referirse a Balbín como referente de la UCR, se rescataba el apoyo brindado al oficialismo en ese duro trance, al tiempo que subrayaba que el radicalismo había descartado públicamente la posibilidad de integrar el nuevo gabinete para afianzarse en su "papel opositor". ${ }^{62}$

\footnotetext{
58 "El desgaste del poder". (marzo de 1974). Redacción, (13), tapa; Gambini, H. (abril de 1974). "El gobierno y la Oposición". Redacción, (14), p. 7; Fela, S. (mayo de 1974). "Muerte y resurrección del verticalismo". Redacción, (15), p. 22; Gambini, H. (junio de 1974). “El modelo argentino”. Redacción, (16), p. 5.

59 “Adónde va la República”. (abril de 1974). Redacción, (14), p. 16.

${ }^{60}$ Pandolfi, R. (julio de 1974). “QQuiénes van a gobernar ahora”. Redacción, (17), pp.12 y 13.

${ }^{61}$ Gambini, H. (julio de 1974). “La muerte de Perón”. Redacción, (17), p. 5.

${ }^{62}$ Pandolfi, R. (julio de 1974). “¿Quiénes van a gobernar ahora”. Redacción, (17), p. 17.
} 


\section{Figura 4. Redacción y su preocupación por el nuevo poder luego de la muerte de Perón}

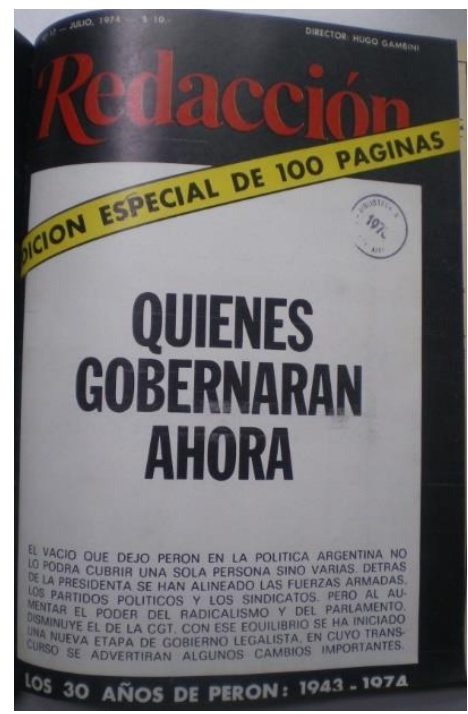

Fuente: julio de 1974, Hemeroteca de la Biblioteca del Congreso de la Nación Argentina.

Cuestionario fue una de las revistas que más tempranamente planteó la inquietud sobre la salud de Perón y el futuro político ante su eventual deceso. En agosto de 1973, cuando aún se discutía quién acompañaría a Perón en la fórmula presidencial, Terragno aseguraba que, a los 77 años, el General no estaba lejos de su muerte o de su debilitamiento intelectual, y por lo tanto el peronismo necesitaba una "mayor precisión a su doctrina". Esa inquietud se enmarcaba en lo que consideraba una "velada guerra civil" entre la izquierda y la derecha de su movimiento, enfrentamiento que, en estilo predictivo, ${ }^{63}$ advertía no sería "breve ni incruento". En tal marco conflictivo Perón era el único que podía contribuir a esa clarificación al designar a qué sectores sociales pretendía representar el peronismo, e institucionalizarlo para evitar "que la lealtad a un hombre (...) siga siendo el principal mérito en el movimiento" y que, en cambio, lo que contara fuera la "lealtad a las ideas". ${ }^{64}$

Poco antes de la asunción presidencial del 12 de octubre, Cuestionario lanzó literalmente desde su tapa lo que parecía ser la pregunta tabú del momento: “¿Y si se muere Perón?" (Figura 5). Para la revista, su eventual desaparición física "agudizaría los conflictos internos del peronismo" y, según las circunstancias, "hasta podría devolver la iniciativa a las Fuerzas Armadas", con el elemento perturbador adicional de que la sucesión quedaría en manos de Isabel, quien no era un factor aglutinante de fuerzas. Sin embargo, la crisis "ya existía” y con Perón solo no bastaba. Había que comprender que un conductor político era siempre "un representante" y que, en definitiva, una fuerza

\footnotetext{
${ }^{63}$ En tanto diagnostica resultados de tipo social y político utilizando el método de interpretación causal determinista (Rivadaneira Prada, 1986; citado por Castelli, 1991, pp. 195-6).

${ }^{64}$ Terragno, R. (agosto de 1973). “El futuro de Perón”. Cuestionario, (4), contratapa.
} 
que llegaba a reunir más del 60 por ciento de la población, como en las elecciones de septiembre de1973, "no depende del ritmo cardíaco de un hombre de 78 años" ${ }^{65}$

\section{Figura 5. Cuestionario lanza desde su tapa la pregunta tabú: “¿ si se muere Perón?"}

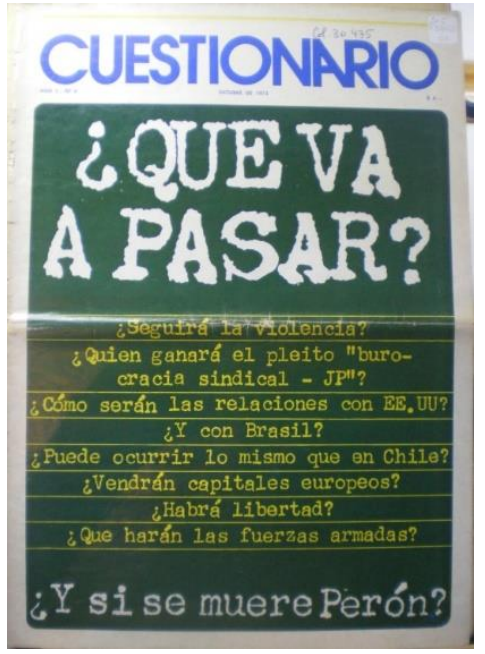

Fuente: octubre de 1973, Hemeroteca de la Biblioteca del Congreso de la Nación Argentina.

La inquietud sobre el eventual fallecimiento de Perón era retomada con todo su peso por Terragno en su contratapa de diciembre, titulada, ya en tono asertivo: "Cuando Perón no esté". ${ }^{66}$ Consciente de que estaba tocando un tema "tabú", 67 marcaba la siguiente paradoja: “Si antes se simulaba que Perón no existía, ahora se simula que Perón es inmortal. Hay un pudor sacramental que impide considerar públicamente la eventualidad de que Perón muera antes de terminar su mandato". Para el director, peronistas y antiperonistas estaban consolidando la idea que el futuro de Argentina dependía de la "vida de Perón", y que una vez fallecido éste el país estaría perdido. De esa manera se estaba asistiendo a una "profecía autocumplida", en tanto al creer lo que podría ser una hipótesis -que luego de la muerte de Perón devendría el "caos"-, se estaban demorando ciertas decisiones y por ese motivo, tras su muerte, la profecía del caos se cumpliría. Lo que Terragno demandaba era que el peronismo realizara con urgencia una "actualización doctrinaria" sobre la base de un "amplio y leal debate ideológico, capaz de culminar en la elaboración de un proyecto revolucionario, explícito y preciso" y no dejarlo para el momento "menos feliz", o sea, cuando la ausencia física del líder se concretara. ${ }^{68} \mathrm{Sin}$ duda, a la luz de los hechos posteriores, se destaca la capacidad premonitoria del director, pero paralelamente su planteo de "actualización"

\footnotetext{
65 “QQué va a pasar?”. (octubre de 1973). Cuestionario, (69), p. 7.

${ }^{66}$ Terragno, R. (diciembre de 1973). "Cuando Perón no esté". Cuestionario, (8), contratapa.

67 "La sucesión”. (abril de 1974). Cuestionario, (12), pp. 3-5.

68 Terragno, R. (diciembre de 1973). “Cuando Perón no esté”. Cuestionario, (8), contratapa.
} 
se volvía por demás abstracto frente a la realidad de proyectos políticos internos que aparecían como absolutamente irreconciliables.

El impacto que supuso la muerte de Perón centró la mirada de Cuestionario sobre el futuro inmediato. ${ }^{69} \mathrm{El}$ titular de tapa, "y ahora ¿QUE?" (simulando las habituales pintadas callejeras de la época) (Figura 6) resumía el sentir de la revista, y seguramente de la sociedad en general, frente a la incertidumbre de la nueva coyuntura. En principio, hacía saber sus "dudas" sobre el rol que tendría el naciente gobierno de Isabel frente a los variados conflictos abiertos. Pero, paradójicamente, aseguraba que el temor a una nueva quiebra del orden institucional la había beneficiado y todos los sectores habían ofrecido un "inmediato acatamiento" a su figura. Aunque reconocía que no era la persona "ideal", era sin embargo la "elegida por el pueblo, como figura accesoria a la de Perón, pero elegida, y legalmente investida". Sobre esa base el gobierno de su viuda era la alternativa "preferible" frente a la eventualidad de su renuncia o un gobierno militar. Con estilo admonitorio, ${ }^{70}$ advertía que debía ser muy cuidadosa en la elección de sus colaboradores, ya que con Perón estos tenían un rol secundario que ahora cambiaría, y que de ninguna manera podría aspirar (ni ella ni nadie) a manejar "a voluntad el peronismo": ese era un "objetivo inalcanzable" para una sola persona. Para Cuestionario tenía que darse el debate que se había postergado en vida de Perón, y por el cual se había bregado desde sus páginas, para así saber si perduraba, si se desintegraba en beneficio de los sectores antipopulares o si lograba forjar el "germen de un nuevo gran movimiento popular". ${ }^{71}$

\footnotetext{
${ }^{69} \mathrm{Y}$ ante el acontecimiento replicó, en una nota especial, la tapa de octubre de 1973 y sus editoriales donde demandaba discutir el escenario político ante un eventual fallecimiento del líder. "La prédica de un año". (julio de 1974). Cuestionario, (15), p. 5.

${ }^{70}$ En tanto exhorta al cumplimiento de reglas, advierte peligros, llama al orden y a la concordia buscando un equilibrio permanente en el sistema frente a las contradicciones que alcanzan niveles de grave enfrentamiento. (Rivadaneira Prada, 1986; citado por Castelli, 1991, pp. 195-6).

71 "Y ahora ¿qué?". (julio de 1974). Cuestionario, (15), p. 3.
} 
Figura 6. Cuestionario y la incertidumbre ante la muerte de Perón

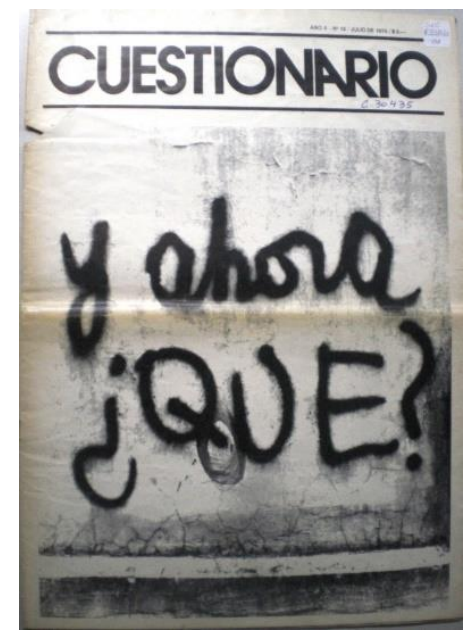

Fuente: julio de 1974, Hemeroteca de la Biblioteca del Congreso de la Nación Argentina.

La contratapa de Terragno, titulada "Sin Perón", complementó el análisis de la nota central y se ancló en la sensación de vacío que había dejado su fallecimiento. Reconocía allí su figura insustituible para la política argentina, pero con un dejo de forzada esperanza en el futuro planteaba que inclusive su ausencia podía tener un signo de maduración para el país y el peronismo si se sabía dar buen cauce a los desafíos que se abrían. ${ }^{72}$

En relación a Carta Política, su primer número, aparecido en la tercer semana de junio, coincidió con lo que a la postre sería la última aparición pública de Perón en el balcón de la casa de gobierno ante una multitud reunida en la Plaza de Mayo. La convocatoria presidencial ese 12 de junio de 1974 fue un intento por recuperar la iniciativa política frente a la pérdida de consenso que venía sufriendo el Pacto Social de parte de sus firmantes (Torre, 2004, pp. 79-80). Sin embargo, la lectura de Carta Política era más sofisticada de lo que esta realidad aparentaba mostrar, en tanto argüía que desde su regreso definitivo el 20 de junio de 1973 Perón se había quedado "sin enemigos" ante la casi total unanimidad del esquema político por él pergeñado y el "exceso de consenso" que se desprendía de ello. ${ }^{73}$ Es que el problema de fondo para la revista no era político ya que había muchos sectores comprometidos con defender la "precaria" institucionalización lograda- sino que los temas pasaban por el desarrollo de la educación, de la sociedad y, principalmente, de la economía, donde efectivamente había problemas "graves" ${ }^{74} \mathrm{y}$ las medidas oficiales intervencionistas y redistributivas no aportaban soluciones concretas. ${ }^{75}$

\footnotetext{
72 Terragno, R. (julio de 1974). “Sin Perón”. Cuestionario, (15), contratapa.

73 "Un hombre en busca de enemigos". (tercera semana de junio de 1974). Carta Política, (1), p. 2.

74 "Un hombre en busca de enemigos". (tercera semana de junio de 1974). Carta Política, (1), p. 4.

${ }^{75}$ F. M., (tercera semana de junio de 1974). “Quien quiere los fines, debe querer los medios”. Carta Politica, (1), p 3.
} 
En torno a la figura de Perón, el historiador Félix Luna ofrecía una semblanza del líder sobre tres presupuestos: "su pragmatismo, su centrismo y su apetencia de poder". Sobre esa base, Perón era como los "papelitos" que cambiaban de colores "según la composición química" en la que se sumergían. Cuando la realidad política viraba hacia la derecha, Perón se ponía "rojo", y cuando esa realidad se "izquierdizaba" se teñía de un "cándido celeste y blanco...". Eso sí, en todos los casos tendía a mantenerse en el "centro" y a tomar "todo el poder posible". ${ }^{76}$ Una mirada que tenía algunos puntos de encuentro con la interpretación de Cuestionario en virtud de su pragmatismo y con la de Extra y Panorama en relación al "centrismo" de Perón.

$\mathrm{Su}$ fallecimiento motivó la inquietud de la revista en relación al futuro institucional inmediato, resumida en la pregunta “QQué va a pasar?" realizada por Grondona. ${ }^{77}$ Desasosiego evidentemente asentado en el valorado equilibro político-institucional que Perón había logrado y que ahora se ponía en peligro. La portada posterior a su muerte enfocaba el acontecimiento desde esta preocupación y era protagonizada por el líder del radicalismo Balbín junto al titular "Las herencias de Perón" (Figura 7). ${ }^{78}$ Carta Política elegía así poner el foco en quien había sido un aliado fundamental del presidente fallecido en la construcción de esa "precaria institucionalización" y quien en las nuevas circunstancias había ofrecido su apoyo a la novel presidenta desde un rol de opositor responsable. ¿Qué intentaba comunicar la tapa de Carta Política? Que, en efecto, Balbín era el genuino "heredero" del último Perón: el de los acuerdos, la "unidad nacional" y la estabilidad institucional. Del líder radical se destacaban su vocación conciliadora, la disposición legalista de su partido y su papel como garante de la estabilidad del sistema político ante los remezones económicos, las pujas intersectoriales y la continuidad de la conflictividad sindical y armada. La UCR funcionaba así como un "péndulo institucional", en tanto era el mejor preparado para estar allí donde el proceso de institucionalización vacilara. ${ }^{79}$

\footnotetext{
${ }^{76}$ Luna, F. (junio de 1974). "Perón, antes y ahora”. Carta Política, (1), p. 21.

77 Grondona, M. (segunda semana de julio de 1974). “El abanico de las conjeturas”. Carta Política, (29), p. 14.

${ }^{78}$ En la nota interior con el mismo título se explicaba que no había una sola herencia de Perón, sino

"herencias" en tanto cada uno de los sectores de la vida nacional creía que el líder fallecido había hablado "para ellos" y que les había asignado a cada uno una "misión". "Las herencias de Perón". (segunda semana de julio de 1974). Carta Política, (2), pp. 2-4.

79 "Soy hombre de Leandro Alem". (julio de 1974). Carta Política, (2), pp. 5-7.
} 
Figura 7. Balbín, el gran “heredero" de Perón para Carta Política

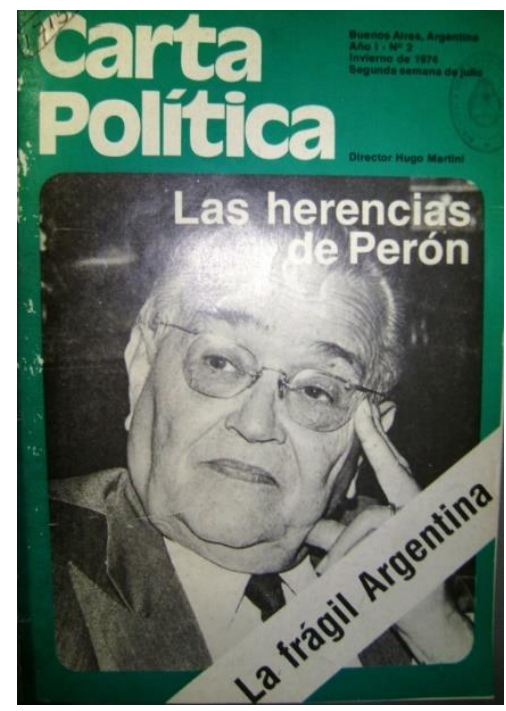

Fuente: julio de 1974, Hemeroteca de la Biblioteca del Congreso de la Nación Argentina.

A tono con esta reivindicación del equilibrio, la nota de tapa destacó que la muerte de Perón no había supuesto ninguno de los cataclismos que se venían vaticinando ante su eventual deceso, y observaba como un aporte a la estabilidad que Isabel hubiera asumido la presidencia como se preveía institucionalmente, confirmando a López Rega - para Carta Política algo lógico pese a las resistencias que despertaba su figura porque, mal que pesara a muchos, había sido un "hombre de Perón"- y a todo su gabinete. De manera que la revista apoyaba enfáticamente el mantenimiento de ese orden institucional, al punto de sostener que el gobierno de Isabel debía ser la continuidad del gobierno de Perón hasta el final de su mandato y que de ninguna manera era momento para entrar en el terreno de las "cabezas cortadas", porque Argentina tenía objetivos a largo plazo como asegurar la paz política y el crecimiento económico. ${ }^{80}$

La apuesta de Carta Política, y de las demás revistas analizadas, era acorde con la coyuntura, en tanto, como señala De Riz (1986, p. 165), la disyuntiva para los diversos actores políticos parecía ser "Isabel o el caos", lo cual obligó al apoyo inicial a la novel presidenta como "heredera personal del líder".

\section{Conclusiones}

En el marco del profundo proceso de conflictividad y crisis institucional que atravesó nuestro país especialmente en el primer lustro de los años setenta, los medios gráficos argentinos vieron condicionado su desempeño profesional, comercial y político. Dentro del ámbito de las revistas políticas de actualidad, en la mayoría de los casos se observa la adopción de un comportamiento pragmático ante la convulsionada agenda política a

\footnotetext{
80 “Las herencias de Perón”. (julio de 1974). Carta Política, (2), pp. 2-4.
} 
119 |“Y ahora ¿qué?” Las revistas políticas argentinas y la muerte de Perón

desarrollar -al menos hasta la muerte de Perón-, tendiente a moderar las críticas al oficialismo en un marco creciente de restricciones a la libertad de prensa.

Del trabajo comparativo entre las posiciones editoriales de las revistas analizadas podemos extraer diversas conclusiones. En principio, observamos que Panorama, Extra y Carta Política fueron las que expresaron una mayor valoración positiva frente al rol estabilizador y el "centrismo" de Perón en su regreso político en 1973, en tanto dique de contención de la voluntad revolucionaria del peronismo de izquierda y como fiel de la balanza para resguardar el orden institucional (con la salvedad que Panorama se inclinó hacia esta posición una vez consolidado el poder peronista, luego de haber apoyado abiertamente al radicalismo). Redacción, desde un perfil más claramente opositor, fue escéptica en torno a la calidad institucional que el peronismo podría ofrecer desde el poder, y en particular destacó el despropósito que suponía la absoluta dependencia del peronismo y de la República de la voluntad de Perón. Cuestionario también relativizó el valor "estabilizador" u ordenador de Perón -remarcando los agudos conflictos existentes bajo su conducción-y alertó por esa excesiva dependencia de su figura, de allí que tempranamente advirtiera sobre las consecuencias de su eventual deceso y exigiera una "actualización doctrinaria" del peronismo. Si bien interpretó el viraje de Perón hacia posiciones más conservadores como parte de su "pragmatismo" por mantener la conducción de su movimiento, desde su sensibilidad de izquierda nacional alertó que ello implicaba un retraso de las reformas que formaban parte del anhelado cambio producido en 1973.

En torno a la salud de Perón, fueron Cuestionario, Panorama y Redacción las más preocupadas por señalar la incertidumbre política que generaba su eventual desaparición física y el juego de intereses que se tramaba detrás de las especulaciones sobre el tema.

Luego de acaecida la muerte del líder, todas las revistas analizadas, con diversos matices, expresaron la necesidad de apoyo a Isabel Perón, dentro de un contexto donde el escenario político parecía polarizado entre las opciones "Isabel o el caos". A tono con su anhelo de estabilidad institucional, "unión nacional" y mantenimiento del orden -en una coyuntura crítica por la situación económica, la lucha desatada dentro del peronismo y una escenario político al filo del desborde- Extra, Carta Política, Panorama y Redacción destacaron al unísono la figura del radical Balbín, al punto de designarlo, en el caso de Carta Política, como el gran "heredero" del último Perón (en tanto para Redacción debía permanecer en su rol de opositor colaborador, pero por fuera del gabinete). La deriva posterior del gobierno de Isabel hacia un extremo verticalismo y la exacerbación del conflicto dentro del peronismo, permite comprender en retrospectiva la sobrevaloración de la figura del líder radical, en tanto las revistas parecían expresar su aprehensión a las potenciales tendencias endógenas y autoritarias que podían caracterizar al nuevo gobierno. Por su parte, Cuestionario no realizó esta apuesta, revalidando su preocupación por la "actualización doctrinaria" del peronismo por la que había bregado, aunque consciente que las nuevas circunstancias lo hacían ya por demás 
improbable, en el marco del retroceso general que venían sufriendo las fuerzas populares, reformistas y de izquierda.

\section{Referencias bibliográficas}

Bonasso, M. (1997). El presidente que no fue. Los archivos ocultos del peronismo. Buenos Aires: Planeta.

Borrat, H. (1989). El periódico, actor político. Barcelona: Gustavo Gili.

Bosoer, F. (2013). Detrás de Perón. Historia y leyenda del almirante Tesaire. Buenos Aires: Capital Intelectual.

Bufano, S. y Teixido, L. (2015). Perón y la Triple A. Las 20 advertencias a Montoneros. Buenos Aires: Sudamericana.

Carman, F. (2015). El poder de la palabra escrita: revistas y periódicos argentinos: 1955-1976. Buenos Aires: Biblioteca Nacional.

Castelli, E. (1991). Manual de periodismo. Buenos Aires: Plus Ultra.

Csipka, J. P. (2013). Los 49 días de Cámpora. Crónica de una primavera rota. Buenos Aires: Sudamericana.

De Riz, L. (1986). Retorno y derrumbe. El último gobierno peronista. Buenos Aires: Hyspamerica.

Fernández Díaz, J. (2018). El hombre que se inventó a sí mismo. Planeta: Buenos Aires.

Franco, M. (2012). Un enemigo para la nación: orden interno, violencia y“ subversión", 19731976. Buenos Aires: Fondo de Cultura Económica.

Garategaray, M. (2009). El León Herbívoro. Notas sobre la última presidencia de Perón. Ponencia presentada en XII Jornadas Interescuelas Departamentos de Historia. Universidad Nacional del Comahue: San Carlos de Bariloche.

Getino, O. (1995). Las industrias culturales en la Argentina: dimensión económica y políticas públicas. Buenos Aires: Colihue.

Godio, J. (1986). Perón. Regreso, soledad y muerte (1973-1974). Buenos Aires: Hyspamérica.

Iturralde, M y Borrelli, M. (2019). “Trasvasamiento generacional no es trasvasamiento ideológico". La revista Extra y el conflicto interno en el peronismo (1973-1974). Trabajos y Comunicaciones, 50. https://doi.org/10.24215/23468971e093.

Manzano, V. (2017). La era de la juventud en Argentina. Cultura, política y sexualidad desde Perón a Videla. Buenos Aires: FCE.

Nahmías, G. (2013). La batalla peronista. De la unidad imposible a la violencia politica (Argentina 1969-1973). Buenos Aires: Edhasa.

Orbe, P. y Napal, M. C. (2019). Periodismo, negocios y política durante el tercer peronismo: la revista Panorama (1973-1975). Question 1 (61). https://doi.org/10.24215/16696581e126.

Perón, J. (1974). Juan D. Perón 1973-1974. Sus discursos, mensajes y conferencias completos. Volumen I. Buenos Aires: Editorial de la Reconstrucción. 
121 |“Y ahora ¿qué?” Las revistas políticas argentinas y la muerte de Perón

Piñero Pacheco, R. (1981). La degeneración del 80. Buenos Aires: El Cid Editor.

Raíces, E. y Borrelli, M. (2019). A la búsqueda de un orden estable. La revista Carta Política, de la muerte de Perón al abandono del Pacto Social (1974). Nuevo Mundo, Mundos Nuevos. https://doi.org/10.4000/nuevomundo.78714.

Rossi, L. (2015). El malestar en la cultura El origen de Carta Política. Año I: 1974. Ponencia presentada en XI Jornadas de Sociología. Universidad de Buenos Aires: Buenos Aires.

Scarzanella, E. (2016). Abril. Un editor italiano en Buenos Aires, de Perón a Videla. Buenos Aires: Fondo de Cultura Económica.

Servetto, A. (2010). 73/76: el gobierno peronista contra las "provincias montoneras". Buenos Aires: Siglo XXI Editores.

Sivak, M. (2010). El Doctor. Biografía no autorizada de Mariano Grondona. Buenos Aires: Aguilar.

Tcach, C. (2002). Heterodoxo diccionario de consignas orales. En C. Tcach (comp.), La política en consignas. Memoria de los setenta (pp. 13-77). Rosario: Homo Sapiens.

Terragno, R. (2005). El peronismo de los 70 (I). De Cámpora a Isabelita. Buenos Aires: Capital Intelectual.

Torre, J. C. (2004). El gigante invertebrado. Los sindicatos en el gobierno, Argentina 1973-1976. Buenos Aires: Siglo XXI.

Ulanovsky, C. (1997). Paren las rotativas. Historia de los grandes diarios, revistas y periodistas argentinos. Buenos Aires: Espasa Calpe.

Yofre, J. B. (2010). El escarmiento. La ofensiva de Perón contra Cámpora y los Montoneros, 1973-1974. Buenos Aires: Sudamericana.

Para citar este artículo:

Borrelli, Marcelo y Orbe, Patricia (2021). “Y ahora ¿qué?” Las revistas políticas argentinas y la muerte de Perón. Anuario de la Escuela de Historia Virtual, 19, 98-121. 